\title{
“PRONTA PARA AJUDAR OS OPERÁRIOS Q̨UE A ELEGERAM": Vereadora Ilza Gouvêa e a militância das tecelãs de Magé/RJ
}

\author{
Felipe Augusto dos Santos Ribeiro *
}

\section{Resumo}

O período compreendido entre 1947 e 1964 foi uma época bastante rica em experiências para os trabalhadores têxteis do município de Magé-RJ, tida por eles como um tempo áureo, de muitas conquistas para a categoria, sobretudo via participação político sindical. Esse contexto coincidiu, justamente, com a ascensão do Partido Comunista do Brasil (PCB) no município, tendo vários de seus militantes sido eleitos como diretores sindicais e vereadores. Ao promoverem um elevado nível de organização e mobilização dos trabalhadores locais, os comunistas conseguiram eleger, mesmo na clandestinidade, por meio de outras legendas, um total de onze vereadores em Magé. Portanto, o presente trabalho tem por objetivo analisar a militância política das tecelãs mageenses, com destaque para a operária Ilza Gouvêa, eleita vereadora em 1950.

Palavras chave: Mulheres Operárias. Partido Comunista do Brasil. Militância Política Feminina.

Desde meados do Século XIX, o município de Magé tornou-se pródigo em abrigar indústrias têxteis, passando de uma região essencialmente agrícola para uma região eminentemente industrial no século seguinte.

Localizado ao fundo da Baía de Guanabara, na Baixada Fluminense, o município chegou a manter, na década de 1940, cinco estabelecimentos têxteis em funcionamento: as fábricas Santo Aleixo, Andorinhas, Pau Grande, Mageense e Cometa, cada uma com cerca de 450 operários.

A presença feminina entre os tecelões de Magé já se fazia presente desde a instalação da primeira fábrica de tecidos no município, a Fábrica Nacional de Santo Aleixo em 1848,

\footnotetext{
* Doutorando em História, Política e Bens Culturais pelo CPDOC/FGV e Mestre em História Social pela FFP/UERJ. Autor da dissertação "Operários à tribuna: vereadores comunistas e trabalhadores têxteis de Magé (1951-1964)”. Email: felipe_ffp@yahoo.com.br.
} 
que inovou ao utilizar mão-de-obra exclusivamente livre. De acordo com o Relatório da Província do Rio de Janeiro (1851, p.28), dos 115 operários contratados para iniciar a produção do estabelecimento e alojados ao redor da fábrica, a imensa maioria era menor de idade, sendo 98 estrangeiros e 17 brasileiros. Dentre eles, 83 eram alemães, vindos de Petrópolis, e 44 eram do sexo feminino.

Ao longo da trajetória do movimento operário mageense, as mulheres operárias foram adquirindo um papel de destaque não apenas no percentual da quantidade de tecelões, mas também na militância política desses trabalhadores, sobretudo de influência comunista. Nesse contexto, a chegada do médico Irun Sant'Anna ao município tornou-se bastante significativa.

Formado em Medicina no ano de 1938, Dr. Irun logo se especializou em Saúde Pública, mais precisamente em Malária. Em 1940, foi nomeado para combater a doença no município de Magé. Filiado ao Partido Comunista do Brasil (PCB), desde a juventude, o médico surpreendeu-se ao encontrar as cinco fábricas de tecidos que funcionavam na região e seu considerável contingente operário. Desde então, passou a mesclar atividades médicas e políticas, tendo notabilizado-se tanto no combate à doença, quanto na mobilização de operários ligados ao PCB, inclusive elegendo vários deles vereadores na Câmara Municipal.

A efervescência comunista foi bastante intensa e promissora no município de Magé entre as décadas de 1940 e 60, tanto que, ao passo que o PCB adquiriu notoriedade na política mageense, a repressão aos militantes e às manifestações do partido cresceu sobremaneira, mesmo após a conquista de sua legalidade partidária, em 1945.

Das reuniões do PCB mageense na clandestinidade surgiu uma geração de operários bastante politizados, tornando-se notória a influência que o médico comunista imprimiu no imaginário dos trabalhadores têxteis de Magé, intensificando um processo de acumulação política que realçou sobremaneira a noção de cidadania desses tecelões.

Para além dessas reuniões clandestinas, os comunistas mageenses organizaram uma série de campanhas e associações, visando à mobilização dos trabalhadores em torno do partido. Uma delas, porém, gostaríamos de destacar, sobretudo por dirigir-se às mulheres operárias ou esposas de operários: a Liga Feminina de Santo Aleixo.

Conforme noticiado pelo Tribuna Popular (jornal editado pelo PCB), essa Liga Feminina foi fundada em 1946, tendo em sua diretoria as senhoras Marcelina Natal, Romilda Ceniro Santana, Maria Natal, Luzia Aquino Santana, Pia dos Santos, Maria Teixeira, Edna Nunes e Clarides Soares Gomes, essa última como presidente. 
Na reportagem intitulada "Lutam as mulheres de Santo Aleixo contra a carestia e a fome”, constavam entre as reivindicações da Liga Feminina a construção de um estabelecimento hospitalar, o conserto das pontes que ligavam Santo Aleixo à Magé, a luta por mais pão, leite e carne, e contra os preços extorsivos dos gêneros de primeira necessidade.

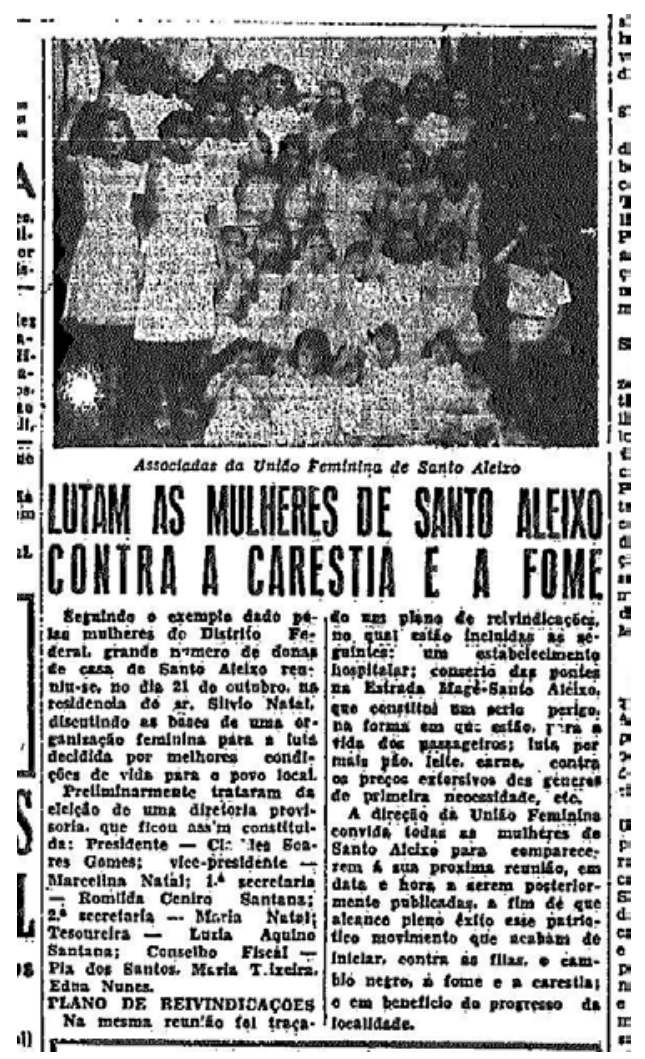

Imagem 1: Fac simile do Tribuna Popular, de 17 de novembro de 1946. p.4. Fonte: Acervo da Fundação Biblioteca Nacional - Brasil.

Seguindo o exemplo dado pelas mulheres do Distrito Federal, grande número de donas de casa de Santo Aleixo reuniu-se, no dia 21 de outubro, na residência do Sr. Silvio Natal, discutindo as bases de uma organização feminina para a luta decidida por melhores condições de vida para o povo local. [...] A direção da União Feminina convida todas as mulheres de Santo Aleixo para comparecerem à sua próxima reunião, em data e hora a serem posteriormente publicadas, a fim de que alcance pleno êxito esse patriótico movimento que acabam de iniciar, contra as filas, o câmbio negro, a fome e a carestia; e em benefício do progresso da localidade (TRIBUNA POPULAR, 1946, p.4).

Em relação ao conserto das pontes que ligam Santo Aleixo a Magé, a Liga Feminina chegou a enviar ao prefeito de Magé um memorial, contendo 356 assinaturas, exigindo o reparo nessas pontes, inclusive fazendo uso do argumento de que Santo Aleixo era o distrito que mais contribuía para os cofres do município, conforme a reportagem "Reparo nas pontes que ligam Magé-Santo Aleixo” (TRIBUNA POPULAR, 1947. p.4). 
Nesse período, o PCB já se articulava para o pleito estadual, que seria realizado em 19 de janeiro de 1947, que elegeria governadores, deputados estaduais e suplentes de senadores. Durante a campanha, o partido lançou em Magé as candidaturas do médico Irun Sant'Anna e da tecelã santoaleixense Natalina Lopes Caldeira para concorrerem ao cargo de deputado estadual. Em panfletos distribuídos na cidade, e apreendidos pela DOPS, os comunistas chamavam a atenção do eleitorado mageense para o programa mínimo do PCB, que seria defendido pelos candidatos inscritos em sua legenda: "homens e mulheres, comunistas ou não, mas todos democratas honestos e antifascistas provados nas duras lutas”.

Eis aí trabalhadores de Santo Aleixo e de Magé o que é assegurado na Constituição de 1946, que somente poderá ser levado à prática se soubermos nos organizar em sindicatos, uniões femininas, camponesas, esportivas ou recreativas, e dando todo vosso apoio na consolidação da Confederação dos Trabalhadores do Brasil [...]. Em vossas mãos estão entregues os destinos da democracia de nossa pátria [...]. Votem nos candidatos da Chapa Popular do PCB, que se comprometem com o povo, a defender no Parlamento Estadual as suas reivindicações mais sentidas e o programa mínimo com que se apresentam para as eleições de 19 de Janeiro [...]. Tudo por 78.000 votos! Tudo pela vitória dos nossos candidatos! (APERJ, s/d).

Apesar da intensa campanha realizada pelos comunistas, com a realização de vários comícios, que tivemos acesso através dos documentos de investigações da polícia política, seus candidatos em Magé não conseguiram se eleger, embora Dr. Irun tenha alcançado a suplência.

Ainda assim, a votação dos comunistas foi bastante expressiva em Magé durante a etapa inicial do processo democrático, vigente no país pós Estado Novo. Nessa eleição estadual de 1947, o PCB despontou como o segundo partido mais votado no município de Magé, alcançando a soma de 1.223 votos, pouco atrás do Partido Social Democrático (PSD) que computou 1.552 votos.

Vale ressaltar que, de 1947 até 1964, apesar da cassação do PCB, o comunistas conseguiram eleger diversos vereadores na Câmara de Magé, através da legenda de outros partidos, em todos os pleitos municipais. Ao todo, foi contabilizado um total de onze vereadores comunistas empossados no período, em sua grande maioria de operários têxteis.

Ainda assim, a votação dos comunistas foi bastante expressiva em Magé durante a etapa inicial do processo democrático, vigente no país pós Estado Novo. Nessa eleição estadual de 1947, o PCB despontou como o segundo partido mais votado no município de 
Magé, alcançando a soma de 1.223 votos, pouco atrás do Partido Social Democrático (PSD) que computou 1.552 votos.

Vale ressaltar que, de 1947 até 1964, apesar da cassação do PCB, o comunistas conseguiram eleger diversos vereadores na Câmara de Magé, através da legenda de outros partidos, em todos os pleitos municipais. Ao todo, foi contabilizado um total de onze vereadores comunistas empossados no período, em sua grande maioria de operários têxteis.

Nas eleições de 03 de outubro de 1950, os comunistas mageenses abrigaram-se no Partido Trabalhista Nacional (PTN) e lançaram diversos candidatos, porém, evitaram mencionar o nome da legenda pela qual concorriam. Durante a campanha, apresentavam-se como “candidatos de Prestes”, assim como os outros comunistas do país.

Como candidata a deputada estadual lançou a operária Edna Nunes, atuante no PCB mageense há bastante tempo, reconhecida pelo seu espírito aguerrido e por ser "brava pra danar”, conforme assinalou Dr. Irun (2006), que se candidatou a deputado federal na mesma eleição. Ambos não se elegeram.

Para a prefeitura de Magé, os comunistas lançaram como candidato Valdemar de Souza, mais conhecido como "Valdo" ou "Russo". Seus adversários à prefeitura foram o médico Radamés Marzullo, do Partido Trabalhista Brasileiro (PTB), e o ex-prefeito Waldemar Lima Teixeira, do PSD, que venceu o pleito. A votação do candidato a prefeito do PTN foi impugnada, a pedido da União Democrática Nacional (UDN), do PSD e do Partido Democrata Cristão (PDC), que o acusaram de ser comunista.

Na eleição para a Câmara de Vereadores o PTN elegeu dois representantes: o eletricitário José Aquino de Santana, mais conhecido como “Zé Soldado”, guarda-fios da Subestação de Energia Elétrica em Santo Aleixo, antigo militante do PCB, cujos filhos eram trabalhadores têxteis e também militantes do partido; e o operário Petronilho Alves, tecelão da Fábrica Pau Grande e comunista atuante no $6^{\circ}$ Distrito, sendo também genro do ex-vereador comunista Feliciano Costa, eleito em 1947. Por ocasião da posse dos parlamentares, porém, Petronilho Alves não foi diplomado. Em seu lugar assumiu como suplente a operária têxtil Ilza Gouvêa, da Fábrica Andorinhas, filha de Osvaldo e Alexandrina, membros atuantes da antiga Aliança Operária, e esposa do ex-operário e líder comunista José Rodrigues.

Alcançando resultados eleitorais significativos, os comunistas se voltaram para a disputa por capital político (BOURDIEU, 1998) nos sindicatos têxteis mageenses, ao passo que também se preocupava com a mobilização do operariado para a eleição de novos 
vereadores. Dessa forma, deram início a uma estratégia bastante eficaz na conquista de maior reconhecimento entre os trabalhadores e na demonstração da força de suas ideias.

A Câmara Municipal de Magé, em 1951, empossou treze vereadores, sendo quatro do PSD, três do Partido Ruralista Brasileiro (PRB), três do PTB, dois do PTN e um da UDN. O presidente da Câmara era o vereador Domingos Bellizzi, do PSD, mesmo partido do prefeito eleito de Magé, Waldemar Lima Teixeira.

VEREADORES EMPOSSADOS NA CÂMARA MUNICIPAL DE MAGÉ EM 1951

\begin{tabular}{|l|c|c|}
\hline \multicolumn{1}{|c|}{ NOME COMPLETO } & PARTIDO & DISTRITO \\
\hline Alcebíades de Castro Teixeira & PRB & Magé \\
\hline Aníbal Magalhães & PSD & Santo Aleixo \\
\hline Antônio Pinheiro de Siqueira & PSD & Inhomirim \\
\hline Domingos Bellizzi & PSD & Magé \\
\hline Domingos José do Amaral Júnior & PTB & Magé \\
\hline Gilberto Câmara & PTB & Inhomirim \\
\hline Ilza Gouvêa & PTN & Santo Aleixo \\
\hline João Seixas Júnior & PSD & Guapimirim \\
\hline José Aquino de Santana & PTN & Santo Aleixo \\
\hline Milton Durão Abrahão & PRB & Inhomirim \\
\hline Moacyr Pimentel & PRB & Magé \\
\hline Modesto Clovis de Castilho & UDN & Guapimirim \\
\hline Virgílio Luiz Nogueira & PTB & Magé \\
\hline
\end{tabular}

Tabela 1. Fonte: Câmara Municipal de Magé. Livro de Atas n.14 (31/01/1951 a 03/11/1954).

Na bancada do PTN, os dois vereadores eleitos eram operários e comunistas. Um deles eletricitário, José Aquino de Santana, e o outro tecelão, Petronilho Alves. Entretanto, este não pôde assumir o mandato por falta de apresentação de documentos necessários, o que só ocorreu no final do mandato, em novembro de 1954. Até a sua posse, exerceu o mandato sua suplente, a tecelã Ilza Gouvêa, que chegou a licenciar-se do cargo por um breve período, devido a sua gravidez, assumindo o segundo suplente do partido, Manoel Carneiro de Azevedo, que não mantinha ligações com o PCB.

A candidata Ilza Gouvêa alcançou a primeira suplência do PTN, tomando posse de seu mandato como vereadora no dia 20 de março de 1951, em virtude do candidato eleito Petronilho Alves não ter sido diplomado como vereador. Ela foi a segunda mulher que assumiu o cargo de vereadora na história do município, lembrando que na legislatura anterior assumiu o cargo Maria Clara da Rocha, substituindo um dos vereadores comunistas cassados em 1948. Entretanto, Ilza Gouvêa foi a primeira e única mulher comunista a assumir a vereança em Magé. 
[...] O $1^{\circ}$ Secretário lê o diploma conferido ao vereador [sic] Ilza Gouvêa, que faz o juramento na forma da Lei e toma posse [...]. Fala o vereador [sic] Ilza Gouvêa, dizendo estar pronta para ajudar o povo, principalmente aos operários que a elegeram [...] (CMM, n.17, fls.113 v-115).

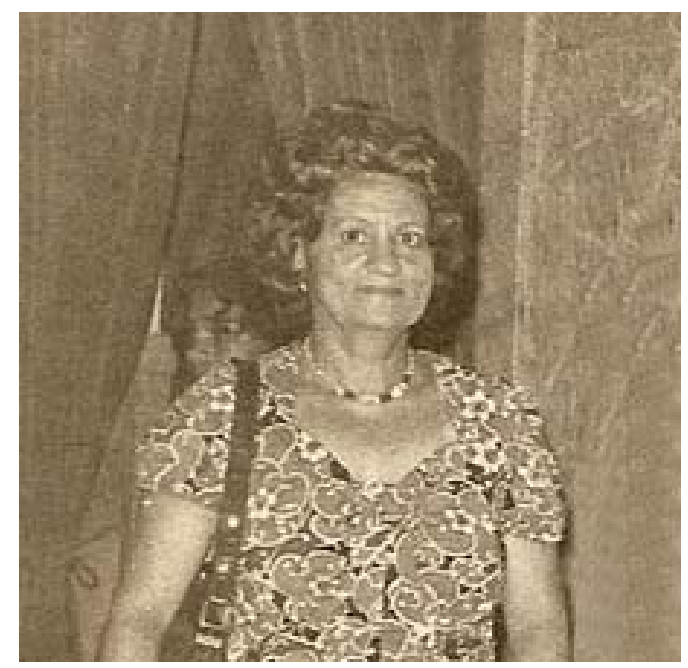

Imagem 2: Ilza Gouvêa. Fonte: Autor desconhecido. Acervo da família.

Coincidentemente, no mesmo dia de sua posse, o periódico comunista Imprensa Popular (que substituiu o Tribuna Popular) publicava uma reportagem sobre as condições de trabalho nas fábricas Andorinhas e Santo Aleixo, destacando inclusive as reivindicações das mulheres operárias mageenses.

[...] O salário médio, mesmo em empresas sugadoras do suor do operário, varia entre 800 a 850 cruzeiros. Mas nas duas fábricas [...] o salário médio é de 600 cruzeiros! [...] O elemento feminino é em alta percentagem requisitado para o trabalho, cerca de 50 por cento. Com isso os patrões têm em vista arrecadar mão de obra mais barata. Não obstante, os patrões estrangeiros da Fábrica Andorinhas não instalaram, como mandam as leis trabalhistas, 'creches' para as mães que ali trabalham, nem proveram o estabelecimento de lavatórios, armários, bebedouros e vestiários privativos de mulheres (IMPRENSA POPULAR,1951. p.5).

Tecelã da Fábrica Andorinhas, Ilza Gouvêa nasceu no distrito de Santo Aleixo, no ano de 1925, tendo sua família participado ativamente das lutas operárias do município. Seus pais, Oswaldo e Alexandrina Gouvêa, conhecidos como “Oscar” e "Xandoca”, respectivamente, atuaram na Aliança Operária, durante as décadas de 1920 e 30.

Na sua juventude, a operária Ilza Gouvêa namorou e se casou com o líder comunista José Rodrigues, ex-operário da Fábrica Santo Aleixo. Seu casamento ocorreu um mês antes 
das eleições de 1950, sendo realizado em Setembro, quando também deixou de trabalhar na fábrica de tecidos.

Durante seu mandato, foram raros os pronunciamentos em plenário. Normalmente, propunha indicações ao parlamento juntamente com seu companheiro de partido. De acordo com as atas da Câmara Municipal de Magé, sem contar o seu discurso de posse, a vereadora Ilza tomou a palavra somente uma vez, no dia 21 de março de 1952, quando o líder de sua bancada, José Aquino de Santana, protestou contra uma provocação recebida por um agente policial ao estar acompanhado da vereadora Ilza Gouvêa. Discursando sobre o ocorrido em plenário, José Aquino de Santana foi interrompido pela vereadora, que "pedindo a palavra, censura veementemente o referido policial por ter lhe faltado o devido respeito, porquanto é senhora casada e de comportamento honesto” (CMM, n.17, fl.65 v).

Ao consultarmos documentos da polícia política no APERJ, percebemos que alguns investigadores consideravam que os vereadores José Aquino de Santana e Ilza Gouvêa fossem casados. Tal equívoco, provavelmente, decorreu pelo fato do marido da vereadora ter passado a assinar seu nome como “José Rodrigues Santana” desde o seu retorno à Magé, conforme consta em sua Certidão de Casamento.

Quanto a sua atuação como parlamentar, o próprio depoimento de seu marido, José Rodrigues, atesta a pouca utilização da tribuna da Câmara, ao afirmar que “o mandato da Ilza foi tranquilo [...]. Pouca coisa importante, mais no nível das reivindicações populares... Minha esposa era de poucas letras, era de falar pouco, se falasse muito se complicava...” (JOSÉ RODRIGUES, 2006).

Além disso, outro fato que nos chamou atenção durante a pesquisa nas atas da Câmara foi o alto índice de faltas da referida vereadora, principalmente no primeiro e no último ano da legislatura. Em 11 de novembro de 1952, a vereadora Ilza Gouvêa solicitou um período de licença “por motivos de saúde”, assumindo então o segundo suplente do PTN, Manoel Carneiro de Azevedo, que nada tinha haver com os comunistas. A parlamentar retornou de licença em Março do ano seguinte, permanecendo até 06 de Novembro de 1954, quando o vereador Petronilho Alves foi diplomado e tomou posse, após solucionar problemas com sua documentação.

Porém, essas diversas faltas da vereadora Ilza Gouvêa decorreram do nascimento de seus três filhos, todos durante seu mandato. Em Junho de 1951 nasceu sua primeira filha, Zélia Maria; em Dezembro do ano seguinte, um menino, Carlos José; e, por fim, em Julho de 1954 nasceu sua caçula, Maíza. As atas da Câmara, portanto, foram bastante omissas em não citar “os motivos de saúde” que provocaram a ausência da referida parlamentar. 
Na realidade, a comunista Ilza Gouvêa notabilizava-se não propriamente por sua atuação como vereadora, mas, sobretudo, por sua atividade junto às operárias, sendo sempre incumbida, juntamente com a tecelã Edna Nunes da Silva, de reunir o elemento feminino em torno do partido. Essas atividades, inclusive, eram bastante monitoradas pelos investigadores da DOPS.

[...] Um informante meu, comunicou-me que os comunistas estiveram reunidos dia 18 deste, das 13 às 13:50 (entravam e saíam, e pouco demoravam dentro da casa), na residência do comunista João Inácio da Silva, marido de Edna Nunes da Silva. [...] Esta reunião foi depois da comunista Ilza Gouvêa, vereadora - candidata de Prestes, ter voltado de uma viagem que fez a Niterói. [...] Supõe terem estado reunidos com qualquer coisa referente ao $1^{\circ}$ de Maio, pois mandando um menino se aproximar da casa, o mesmo voltou falando que não podia ouvir bem, porém ouviu alguém pronunciar o dia $1^{\circ}$ de Maio. [...] Entraram e saíram da casa os seguintes comunistas: Euzébio de Souza, José Aquino de Santana, Ilza Gouvêa, Manoel Pessanha, Petronilho dos Santos [Alves], Agenor dos Santos (juntos os dois últimos), Dr. Irun Sant'Anna (esteve cinco minutos) e Antônio Inácio da Silva. [...] Não saiu pessoa alguma com embrulho, bem como não entrou, salvo Ilza Gouvêa, que entrou com uma bolsa de fazer compras, de lona, saindo com a mesma [...] (APERJ, s/d).

Durante seus mandatos, os vereadores comunistas mageenses tiveram que enfrentar uma severa realidade: o fortalecimento do anticomunismo. Nesse contexto, em diversos momentos da legislatura de 1951-1954 os vereadores comunistas foram combatidos por seus pares. Em meio aos debates em plenário, os vereadores, Modesto Clovis de Castilho e Milton Durão Abrahão, chegaram a declarar, respectivamente, que "era anticomunista até a raiz dos cabelos” e que "a palavra comunismo devia ser abolida”. Dessa forma, os comunistas mageenses recorrentemente tinham suas proposições recusadas em plenário.

Ao apresentarem na Câmara uma moção de apoio ao petróleo nacional, os vereadores José Aquino de Santana e Ilza Gouvêa tiveram sua proposta rejeitada sob a alegação de que ela "tinha um cunho do Dr. Irun Sant'Anna”, conforme discurso do vereador Milton (CMM, n.17, fl.82).

O médico Irun Sant'Anna era o coordenador do Movimento Fluminense dos Partidários da Paz, com sede em Niterói e intimamente ligado ao PCB. De acordo com investigações da polícia política, o Dr. Irun Sant’Anna, o vereador José Aquino de Santana e o tecelão Petronilho Alves chegaram a comparecer à residência do prefeito Waldemar Lima Teixeira (assinalado equivocadamente como Waldemar de Castro no documento do APERJ), convidando-o a fazer parte da direção da campanha pela paz e contra a bomba atômica, sendo repelidos pelo prefeito diante de "tal ousadia”, já que ele era adversário direto dos comunistas (APERJ, s/d). 
Em outra ocasião, José Aquino de Santana protestou em plenário contra a atitude de policiais que "maltrataram pessoas que vinham angariando assinaturas". Tratava-se de um abaixo-assinado para a volta da carrocinha de pão e leite em Santo Aleixo. Porém, o vereador Aníbal Magalhães justificou a postura da polícia, "porquanto as duas senhoras [que recolhiam assinaturas] infelizmente são suspeitas, sendo que uma é esposa de um comunista fichado” (CMM, n.17, fl.104)

Sobre a Campanha da Paz, defendida pelos vereadores José e Ilza por meio de moções que foram apresentadas à Câmara, o vereador Virgílio Luiz Nogueira declarou que "essa questão da paz, propagada pelos comunistas, é um caso igual ao da raposa que acaricia a ovelha para abocanhá-la” (Id, fl.107).

De fato, ao analisarmos o mandato parlamentar desses comunistas mageenses, percebemos que todos eles, independente de sua atuação profissional, buscaram dar voz e vez aos operários do município, lutando por melhores condições de vida e trabalho e forjando um discurso vigoroso em prol dos seus interesses mais prementes. Esse capital político, portanto, transfigurava-se em poder simbólico (BOURDIEU, 1998), fortalecendo a crença de que esses parlamentares comunistas representavam na Câmara todos os trabalhadores mageenses, como autênticos “operários à tribuna”.

Desse modo, o presente artigo abordou a trajetória do movimento operário de Magé sob o enfoque específico da militância feminina, valorizando a atuação de uma figura específica, que ocupou um cargo de relevância na política mageense, a vereadora Ilza Gouvêa. Tendo em vista a significativa renovação nos estudos sobre o movimento operário nas últimas décadas, acreditamos que a pesquisa apresentada possa contribuir para a abordagem de novos temas na historiografia brasileira, anteriormente não tratados ou tidos como secundários.

\section{“READY TO HELP THE WORKERS WHO ELECTED HER": Councillor Ilza Gouvêa and the militancy of the weaver women of Magé, Rio de Janeiro state}

\section{Abstract}

The period between 1947 and 1964 was a time of rich experiences for the textile workers of the municipality of Magé, in state of Rio de Janeiro. It was regarded by the workers as a golden period of many achievements for workers of their category, especially through political and trade union participation. This context coincided precisely with the rise of the Communist Party of Brazil (PCB) in the city, and several of its militants were elected as union directors and councilors. By promoting a high level of organization and of mobilization of the local workers, the communists managed to secretly elect, under different banners, a total of eleven councillors in 
Magé. In this context, the study aims to examine the political militancy of the weaver women of Magé, especially the weaver Ilza Gouvêa, who was elected as a councillor in 1950.

Keywords: Working Women. Communist Party of Brazil. Women's Political Activism.

\section{Referências}

ARQUIVO PÚBLICO DO ESTADO DO RIO DE JANEIRO (APERJ). Prontuário individual do Dr. Irun Sant’Anna, registrado sob o número 13.573, gaveta 175.

BATALHA, Cláudio Henrique de Moraes; SILVA, Fernando Teixeira da; FORTES, Alexandre (org.). Culturas de classe: identidades e diversidade na formação do operariado. Campinas, SP: UNICAMP, 2004.

BOURDIEU, Pierre. A representação política: elementos para uma teoria do campo político. In: . O poder simbólico. Rio de Janeiro: Bertrand Brasil, 1998. 2 ed.

CÂMARA MUNICIPAL DE MAGÉ (CMM). Livro de Ata n.17 (31/01/1951 a 03/11/1954).

IMPRENSA POPULAR. Rio de Janeiro: 20 de março de 1951

JOSÉ RODRIGUES, ex-operário e líder comunista, concedida ao autor, em 04 de agosto de 2006.

MELLO, Juçara da Silva Barbosa de. Identidade, memória e história em Santo Aleixo: aspectos do cotidiano operário na construção de uma cultura fabril. São Gonçalo, RJ: Dissertação de Mestrado em História Social da FFP/UERJ, 2008.

RIBEIRO, Felipe Augusto dos Santos. Operários à tribuna: vereadores comunistas e trabalhadores têxteis de Magé (1951-1964). São Gonçalo, RJ: Dissertação de Mestrado em História Social da FFP/UERJ, 2009.

RIO DE JANEIRO (PROVÍNCIA). Relatório apresentado ao Exmo. Vice-Presidente da Província do Rio de Janeiro, o Comendador João Pereira Darrigue Faro, pelo Presidente o Conselheiro Luiz Pedreira do Couto Ferraz, por ocasião de passar-lhe a Administração da mesma Província no dia 5 de maio de 1851. Província do Rio de Janeiro: s/d, 1851.

SANT’ANNA, Irun. Médico e ex-líder comunista, entrevista concedida ao autor, em 06 de abril de 2006.

SANT’ANNA, Irun. Brasil: País sem Futuro?. Rio de Janeiro: Imprimatur, 1997.

TRIBUNA POPULAR. Rio de Janeiro: 17 de novembro de 1946.

. Rio de Janeiro: 11 de janeiro de 1947.

Recebido em: $16 / 08 / 2010$

Aprovado em: 14/03/2011 